\title{
Expanding the top rungs of the extremity reconstructive ladder: targeted muscle reinnervation, osseointegration, and vascularized composite allotransplantation
}

\author{
Saïd C. Azoury', Andrew Bauder ${ }^{1}$, Jason M. Souza², John T. Stranix ${ }^{3}$, Sammy Othman ${ }^{1}$, Christine \\ McAndrew ${ }^{4}$, Scott M. Tintle ${ }^{2,4}$, Stephen J. Kovach ${ }^{1,4}$, Lawrence Scott Levin ${ }^{1,4}$ \\ 1Division of Plastic Surgery, Department of Surgery, University of Pennsylvania, Pennsylvania, PA 19104, USA. \\ 2Department of Orthopaedic Surgery, Walter Reed National Military Medical Center, Bethesda, MD 20889, USA. \\ ${ }^{3}$ Department of Plastic Surgery, University of Virginia, Charlottesville, VA 22908, USA. \\ ${ }^{4}$ Department of Orthopaedic Surgery, University of Pennsylvania, Pennsylvania, PA 19104, USA
}

Correspondence to: Dr. Lawrence Scott Levin, FACS; Paul B. Magnuson Professor of Bone and Joint Surgery; Chairman, Department of Orthopaedic Surgery; Professor of Surgery (Plastic Surgery); Penn Medicine University City; 3737 Market Street, 6th Floor, Philadelphia, PA 19104, USA. E-mail: scott.levin@pennmedicine.upenn.edu

\begin{abstract}
How to cite this article: Azoury SC, Bauder A, Souza JM, Stranix JT, Othman S, McAndrew C, Tintle SM, Kovach SJ, Levin LS. Expanding the top rungs of the extremity reconstructive ladder: targeted muscle reinnervation, osseointegration, and vascularized composite allotransplantation. Plast Aesthet Res 2020;7:4. http://dx.doi.org/10.20517/2347-9264.2019.44
\end{abstract}

Received: 26 Oct 2019 First Decision: 16 Jan 2020 Revised: 17 Jan 2020 Accepted: 20 Jan 2020 Published: 12 Feb 2020

Science Editor: Matthew L. Iorio Copy Editor: Jing-Wen Zhang Production Editor: Jing Yu

\begin{abstract}
Osseointegration (OI), targeted muscle reinnervation (TMR), and vascularized composite allotransplantation (VCA) are just a few ways by which our reconstructive ladder is evolving. It is important to recognize that amputation does not necessarily denote failure, but surgeons should strive to find ways to provide these patients with means for obtaining better satisfaction and quality of life postoperatively. TMR and OI have added options for mutilating lower extremity injuries that necessitate amputation. More recently, the senior author (Levin LS) described the "penthouse" floor of the reconstructive ladder being VCA. Despite the advances in VCA over the last 20 years, there are many challenges that face this discipline including indications for patient selection, minimizing immunosuppressive regimens, standardizing outcome measures, establishing reliable protocols for monitoring, and diagnosing and managing rejection. Herein, the authors review TMR, OI, and VCA as additional higher rungs of the reconstructive ladder.
\end{abstract}

Keywords: Targeted muscle reinnervation, osseointegration, vascularized composite allotransplantation, salvage, reconstruction

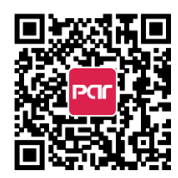




\section{INTRODUCTION}

Harold Gillies introduced the reconstructive ladder for traumatic extremity wounds based on his experience during World War I. Decades later, the senior author (Levin LS) revisited this concept when he coined the collaborative orthoplastic approach between orthopedic and plastic surgeons in extremity reconstruction ${ }^{[1,2]}$. He elaborated on the necessity of a surgeon to be well versed with the various rungs of the reconstructive ladder. Although variations to the original ladder have been described as the reconstructive armamentarium expands with time, the basic tenants remain largely unchanged ${ }^{[3-7]}$. Most descriptions begin with healing by secondary intention on the lowest rung ${ }^{[3]}$. The next lower-level rungs of the ladder include simpler reconstructive options such as the use of split-thickness skin grafts and local tissue rearrangements and the higher rungs represent complex techniques such as free tissue transfer. In general, the simplest option that is able to cover the defect adequately and replace the missing tissue components should be the reconstruction of choice. However, it is understood that a more complex option such as free tissue transfer may be more appropriate even when simpler means achieve closure, such as the cases of severe traumatic wounds with associated fracture repair, hardware, or in the case of oncologic reconstruction when future radiation is anticipated.

Targeted muscle reinnervation (TMR) and osseointegration (OI) have added additional options for mutilating lower extremity injuries that necessitate amputation ${ }^{[8-13]}$. More recently, the senior author Levin $^{[14]}$ described the "penthouse" floor of the reconstructive ladder being vascularized composite allotransplantation (VCA). Despite the successes of prosthetic technology and targeted muscle reinnervation, transplantation offers the ability to restore sensation, fine motor control, and tactile aesthetics while improving overall quality of life ${ }^{[15,16]}$. Herein, the authors review TMR, OI, and VCA as additional higher rungs of the reconstructive ladder [Figure 1].

\section{TARGETED MUSCLE REINNERVATION}

\section{Background}

When a limb is lost, there are residual muscles rendered incompetent without a joint to act across. Similarly, there are nerves that not only are purposeless without distal targets to reinnervate, but can also become a functional hindrance should they form a chronically painful neuroma. TMR was originally developed to make use of these redundant muscles and nerves in amputees for improved upper extremity prosthetics. In TMR, nerves transected during amputation are coapted to nearby motor nerves of redundant muscles, providing a conduit to grow along and a muscle to reinnervate. The muscle acts as a biologic amplifier, creating a myoelectric signal that can be picked up through surface electromyography (EMG). This signal detection can be further amplified surgically by superficializing and separating the myoelectric unit from other nearby signals. Signal mapping and feedback then allows for complex movement of a myoelectric prosthesis.

Evidence for the functional capabilities of TMR in providing advanced prosthetic control came in the form of myoelectrical signal decoding involving physical and practical movements with a prosthetic arm. As research evolved, it was shown that pattern recognition technology could allow for intuitive movementlearning, potentially enhancing both control and timing of movements through the prosthetic limb as an alternative to conventional prosthetics that were plagued with slower learning due to a rather unintuitive motion process ${ }^{[17]}$. The research demonstrated that not only is TMR effective in allowing for complex physical movements, but was also efficient in signal transmission and producing these movements relatively quickly, a crucial consideration in functional validity ${ }^{[17]}$.

Initial reservations in employing TMR included the possibility of creating more nerve pain during the procedure $^{[17]}$. Coapting a nerve that is transected during amputation to a previously intact motor nerve 


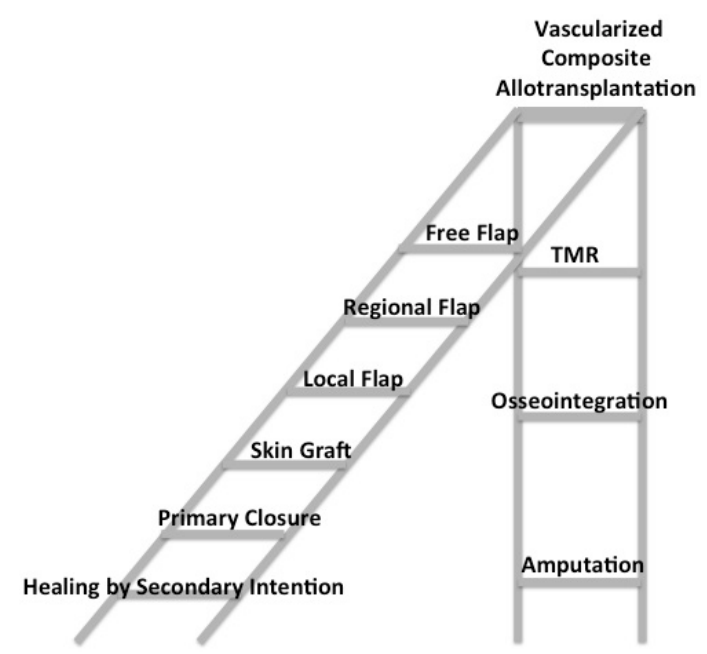

Figure 1. Expanded reconstructive ladder with targeted muscle reinnervation, osseointegration, and vascularized composite allotransplantation. TMR: targeted muscle reinnervation

necessitates creating a proximal motor nerve that is now disconnected and left with no target. However, unlike pure sensory or mixed motor-sensory nerves, these cut pure motor nerves do not form symptomatic neuromas. In fact, contrary to initial reservations, TMR was found to substantially reduce post-amputation pain in upper extremity amputees ${ }^{[18]}$.

The discovery that TMR had the potential to reduce post-amputation pain drastically expanded its indications. The majority of amputees suffer from chronic pain after amputation that can prevent fitting of a prosthesis. While a state-of-the-art myoelectric prosthesis may not be practical for every amputee, a procedure with the potential to reduce chronic pain ballooned in popularity amongst amputees. With this in mind, surgeons have now turned to employing TMR at the time of amputation to prevent postamputation pain ${ }^{[19]}$.

Below, we provide an overview of the indications, techniques, and future directions of TMR in upper and lower extremity amputees, both at the time of amputation and as a secondary procedure. With additional experience using TMR and advancements in prostheses, we will continue to see a shift in functional expectations after amputation from both surgeons and amputees alike.

\section{Upper extremity TMR}

The development of upper extremity TMR was primarily driven by the desire for more natural, intuitive prostheses. Loss of a hand or upper extremity is profoundly limiting. While body powered prostheses help fill this functional void, they cannot recapitulate all of the degrees of freedom of a human upper extremity, particularly with higher-level amputations. They also do not allow for simultaneous movements across multiple joints. As such, there was a push to overcome the shortcomings of traditional prosthesis, chiefly funded by the Defense Advanced Research Projects Agency Revolutionizing Prosthetics Program ${ }^{[20]}$.

TMR was an answer to the call for more intuitive, higher capability prosthetic control. By providing a neural interface with the prosthetic using multiple discrete high-amplitude EMG signals, it has exhibited excellent results for real time control of upper extremity myoelectric prostheses for the last decade $e^{[17,21,22]}$. The upper extremity amputee now has several commercially available myoelectric prosthetic options to choose from ${ }^{[21,23]}$. Moreover, as signal processing and pattern recognition algorithms continue to improve the neural interface between patient and prosthetic, amputees benefit from more natural prosthetic movement ${ }^{[24,25]}$. 

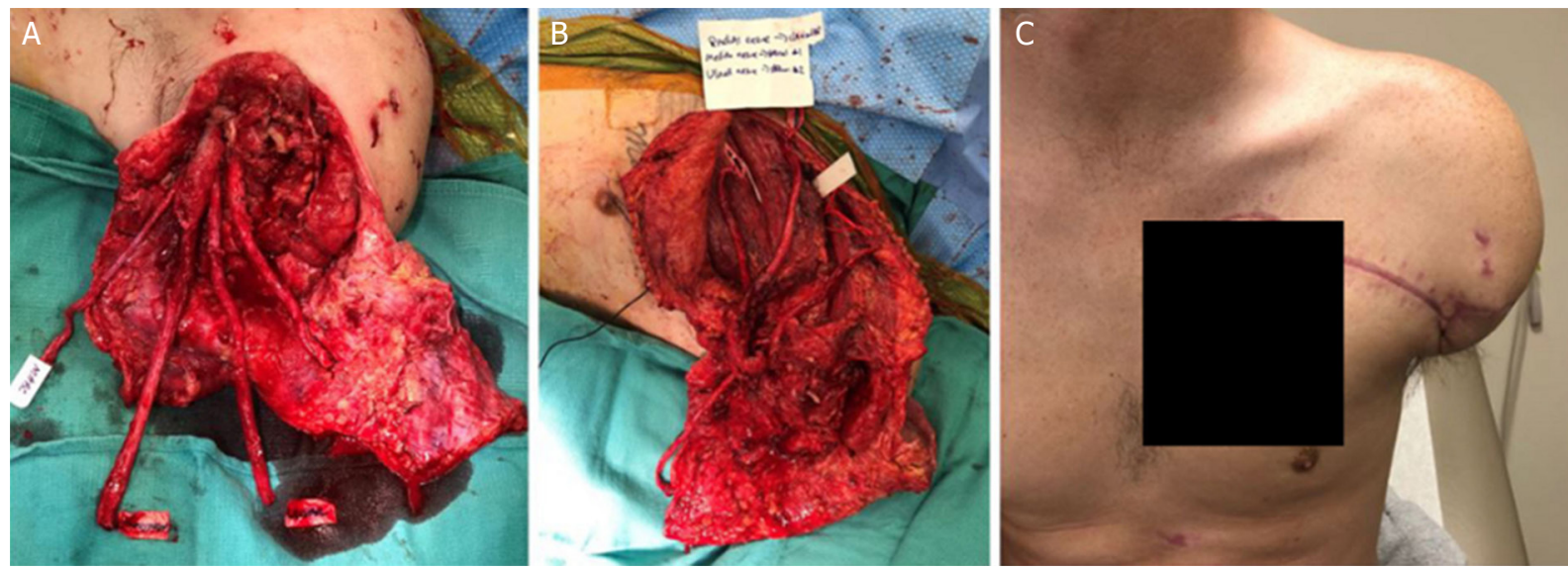

Figure 2. Example of targeted muscle reinnervation at the axillary level in a patient with an unsalvageable upper extremity from a drag racing accident: (A) the careful dissection of musculocutaneous, median, ulnar, and radial nerve; (B) the coaptations of these nerves to the motor endpoints of the ispsilateral pectoralis major; and (C) the patient is well healed at three-month follow up with no pain

\section{Upper extremity TMR - technical considerations}

TMR in the upper extremity is commonly performed at one of three levels: axillary (shoulder disarticulation), transhumeral, and transradial. Regardless of the level of amputation, successful TMR for the purposes of myoelectric prosthetic control relies on creating the highest amplitude, most discrete EMG signal possible. This, in turn, depends on both completely disrupting the native innervation to the recipient muscle to provide a good stimulus for nerve ingrowth and performing the nerve coaptation near the motor nerve entry into this muscle to limit ingrowth distance. Recipient motor nerve/muscle units should also be superficialized and separated from one another if possible. This allows easy decoding of EMG signals via surface electrodes, although pattern recognition can overcome signal cross-talk in many cases.

The surgical rationale and specific nerve transfers at all three levels has been previously described in detail ${ }^{[26-28]}$. At the axillary level, this involves denervating the pectoralis major and coapting the musculocutaneous, median, ulnar, and radial nerves to motor endpoints of separated slips of pectoralis [Figure 2]. At the transhumeral level, TMR requires partial preservation of native signals: the radial signal to the long head of triceps and musculocutaneous signal to long head of biceps are left intact. The median nerve is then typically coapted to the short head of biceps, the radial nerve to the lateral head of triceps, and the ulnar nerve to the brachioradialis. TMR at the transradial level is even less prescriptive than in more proximal upper extremity amputations due to the availability of numerous recipient muscles that can easily be superficially relocated ${ }^{[27]}$. However, at the very least, distal targets for the median, ulnar, radial sensory, and lateral antebrachial cutaneous nerves must be created.

As we have become more familiar with upper extremity TMR at our institution, we have increasingly appreciated the intra-operative creativity involved in formulating a reconstructive TMR plan. No two injuries are the same, and they rarely abide by the surgical game-plan, except at the shoulder disarticulation level. We have also found that, even in a busy metropolitan area, finding a physical therapist well familiar with training for myoelectric prostheses can be difficult. Maintaining clear communication with this therapist is critical, as successful prosthetic use depends largely on rehabilitation and monitored feedback.

\section{Upper extremity TMR - future directions}

Future developments in TMR for the upper extremity will continue to work towards more natural myoelectric prosthetic control. OI prostheses stand to stabilize the patient-prosthetic interface, thereby limiting movement at surface electrodes for more reliable EMG directed prosthetic movement ${ }^{[2]}$. Individual 
fascicular transfer may allow even greater prosthetic control through the creation of an array of individual EMG signals ${ }^{[30]}$. Finally, while all currently available prostheses rely on visual feedback, future prostheses will integrate a sensory feedback loop to allow more effective patient interaction with their environment ${ }^{[21]}$.

Finally, as new surgical techniques develop, so will indications for TMR versus transfers of existing musculature for prosthetic and pain control. Already, it is possible for metacarpal level amputees to obtain excellent finger function with the starfish procedure, in which existing interosseous muscles are dorsally transposed to create a reliable myoelectric signal ${ }^{[31]}$. In this same patient, a sensory neuroma may be resected and the nerve coapted to a motor nerve to the volar interosseous for pain control. Future success will depend on balancing pain control and function with the most effective surgical technique available.

\section{Lower extremity TMR}

While the use of myoelectric prostheses in the upper extremity is somewhat common, it has been modest in the lower extremity ${ }^{[32]}$. This is likely partially related to the relatively recent introduction of lower extremity TMR when compared to the upper extremity. However, it also appears that sensory and proprioceptive feedback of both the amputated limb/prosthesis and the contralateral unaffected limb play a much more important role in developing an intuitive and natural lower extremity prosthesis. Moreover, in the absence of widespread TMR in the lower extremity, there has been some success in developing myoelectric prostheses that rely on EMG signals from the existing innervated musculature in the amputated limb ${ }^{[3,34]}$. Although TMR in the lower extremity may allow more nuanced control of a myoelectric prosthesis, it is possible to control movement as distal as the ankle even with a transfemoral amputation using pattern recognition from the remaining thigh musculature ${ }^{[35]}$.

In the absence of widely available lower extremity prostheses that rely on TMR, much of the conversation surrounding lower extremity TMR has focused on treating and preventing nerve-related pain. For decades, traction neurectomy was the standard of care during amputation, which has proven ineffective in both preventing and relieving post-amputation pain ${ }^{[36]}$. For many patients, the decision to amputate is driven by chronic pain, and they are frustrated to find that they trade the pain prior to amputation for new forms of chronic pain after amputation.

This new pain includes pain at their residual limb site, known as residual limb pain (RLP), and painful sensations in their absent extremity, known as phantom limb pain (PLP). RLP is usually due to neuroma formation. These neuromas stem from the terminal sprouts that form at a transected nerve end after injury primarily and are comprised of disorganized, sensory nerve fibers. PLP is thought to be due to sensorycortical remapping over time and an altered perception of pain. With standard amputation methods, the rates of post-amputation pain were astounding, with over 55\% of longstanding amputees suffering from RLP, and the prevalence of PLP after lower extremity amputation ranging as high as $85 \%{ }^{[37-40]}$.

Lower extremity TMR was first employed to treat the pain many of these existing amputees had suffered from for years. While several prior methods had achieved moderate success in treating post-amputation nerve pain, such as implanting nerves into bone, veins, or muscle ${ }^{[41-43]}$, these methods do not treat the underlying pathophysiology - they simply provide some mechanical masking of neuromas so they are less likely to result in pain. Conversely, TMR prevents the formation of disorganized nerve growth that results neuromas by providing a pathway for nerves to grow down and a denervated target to reinnervate.

After its established success as a secondary intervention for post-amputation neuromas, attention shifted to the use of TMR at the time of amputation as a means to prevent pain ${ }^{[4]}$. Several case series have demonstrated excellent results, although efforts at conducting a randomized control trial comparing TMR to standard methods (i.e., implantation into muscle) were thwarted by patient refusal of randomization due 


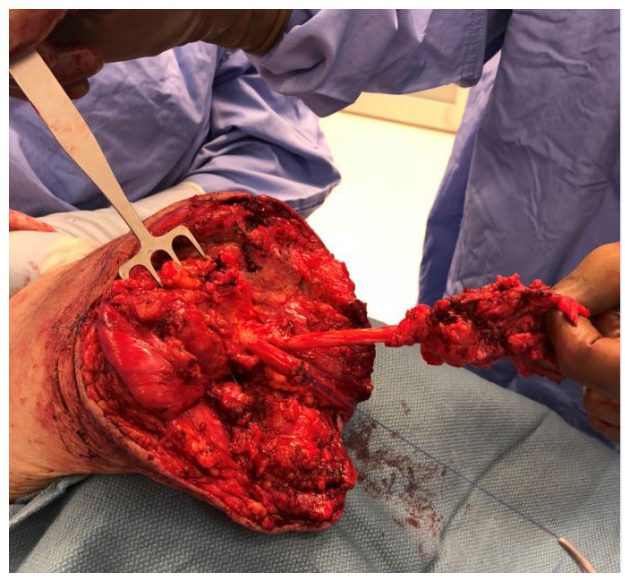

Figure 3. Dissection of a large neuroma in the common peroneal nerve of a transfemoral amputee with severe neuroma pain. Note the haphazard organization of the neuroma

to communication between amputees ${ }^{[45]}$. The majority of TMR that we currently perform at our institution is in coordination with vascular and orthopedic surgeons at the time of amputation. This has re-framed amputation from failure on the part of the surgeon and the end of the surgeon-patient relationship to the beginnings of a new collaborative reconstructive relationship that results in less post-amputation pain and the possibility of more advanced prosthetic use.

\section{Lower extremity TMR - technical considerations}

TMR in the lower extremity is commonly performed at the transfemoral level with above the knee amputation (AKA) and transtibial level with below the knee amputation (BKA). In contrast to upper extremity TMR, which can require more creativity, lower extremity TMR is often more formulaic. When performing TMR for the management or prevention of neuroma pain, the specific motor nerve recipients are much less important because they do not have to be superficial or separated from other nearby signals.

In the case of secondary neuroma treatment, the symptomatic nerve is isolated (usually through an incision separate from the amputation site), the neuroma resected, and the fresh nerve end is coapted to a nearby motor nerve recipient [Figure 3]. In the case of primary TMR, each pure sensory and mixed motor/sensory nerve must be coapted directly to a motor nerve. During an AKA, this includes the posterior cutaneous nerve of the thigh, the saphenous nerve, the common peroneal nerve, and the tibial nerve. During a BKA, this includes the tibial nerve, the deep peroneal nerve, the superficial peroneal nerve, and the sural nerves (medial and lateral).

Similar to the upper extremity, many of these initial surgical techniques and much of the continued data for TMR originates from Dumanian and colleagues at Northwestern. They have populated the literature with roadmaps for TMR at both the tranfemoral and transtibial levels, including the common locations of frequently found motor nerves that can be used for coaptation ${ }^{[46,47]}$. We found these guides particularly helpful in our initial forays into TMR. Since then, we have realized that finding motor nerves in practice is much more reliant on intraoperative nerve stimulation than was first understood [Figure 4].

When available, we typically use a biphasic nerve stimulator (Checkpoint Surgical; Cleveland, OH) because repeated stimulation with this system does not result in neuronal fatigue. The stimulator is set at a moderate pulse duration and $2 \mathrm{~mA}$ for anterograde stimulation or $20 \mathrm{~mA}$ for retrograde stimulation. Retrograde stimulation is often particularly useful. In fact, we have found that tracing proximal motor nerve exit locations from a transected nerve is the most expeditious way to find suitable motor nerve 


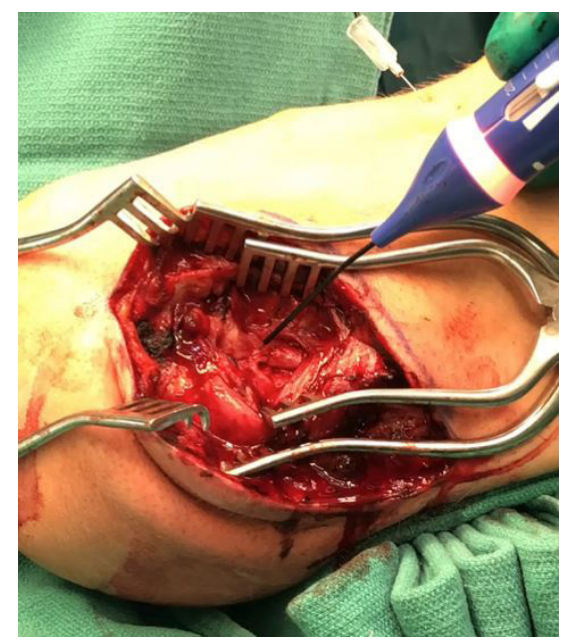

Figure 4. Demonstration of intraoperative nerve stimulation to identify appropriate motor nerve recipients

recipients for our transfers. Once suitable recipient nerves are found, performing the nerve coaptations is often the least time consuming and most straightforward portion of the case.

As our experience in lower extremity TMR has matured, we have learned a number of other useful lessons. First, when performing secondary TMR, differentiating between neuroma pain and other chronic pain conditions cannot be overstated. Neuroma pain is isolated to a specific anatomic distribution and relieved with the administration of a block to the offending nerve ${ }^{[48]}$. While the optimal timing for TMR to treat post-amputation pain is unclear, we do know that patient perception of pain is altered due to chronic pain. This global alteration in pain perception is much more difficult to treat than specific neuroma pain and may not be corrected by TMR performed long after the initial amputation. Second, communication with surgical colleagues performing the amputation is paramount. Reconstructive bridges can easily be burned during the amputation. It pays to be present during the first few amputations performed by a surgical colleague and for the surgeon performing the amputation to have a working knowledge of the purpose and requirements of successful TMR. Notably, intraoperative nerve stimulation will prove ineffective after 30-60 min of tourniquet time. Thus, if TMR is performed at the time of amputation, the amputation should be performed without tourniquet or with a short tourniquet run. Finally, while donor and recipient nerves can easily be accessed through a BKA site, this is not the case during an AKA. The patient must be flipped prone for access to the posterior femoral cutaneous nerve of the thigh and the more proximal motor nerve recipients of the posterior thigh musculature. If the patient is not stable enough for an intraoperative position change, a guillotine amputation can be performed and staged TMR can be undertaken at the time of formal amputation/closure, with the patient positioned prone for this second procedure.

\section{Lower extremity TMR - future directions}

While TMR has gained the most traction of any treatment for post-amputation neuroma pain to date, it is worth noting that it is not the first surgical alternative to traction neurectomy, nor is it the only currently popular method ${ }^{[49]}$. A recent meta-analysis noted that any surgical intervention other than traction neurectomy or nerve capping yielded over a $75 \%$ success rate for relieving neuroma pain after amputation $^{[50]}$. The current literature is lacking in head-to-head comparisons between TMR and these other methods, most importantly with regenerative peripheral nerve interfaces (RPNI).

RPNI is a progression on the decades-old technique of implanting nerve into muscle that has shown promising results for treatment of neuroma pain ${ }^{[51]}$. Muscle grafts are wrapped around the end of donor 
nerves and provide a denervated recipient bed for subsequent reinnervation via a mechanism similar to $\mathrm{TMR}^{[52]}$. Feasibly, these nerve/muscle units could also be used to form a neural interface with a myoelectric prosthesis, but current studies have been limited to animal models thus $\mathrm{far}^{[53]}$. The main benefit of RPNI is its surgical efficiency because the time consuming process of identifying appropriate recipient motor nerves is omitted. At our institution, we employ RPNI as a backup to TMR in unstable patients or when donor nerves are limited due to scar burden or other unfavorable patient pathology.

Finally, the vast majority of the surgical experience with TMR in the lower extremity is in trauma or oncologic patients. These patients represent a different cohort than the majority of amputees, who suffer from limb loss secondary to diabetes and vascular disease and are much more likely to experience longstanding pre-amputation neuropathy. One of the main unanswered questions is whether TMR is effective for pain relief and prevention in the diabetic vasculopath. We seek to answer this question in the near future at our institution.

\section{OSSEOINTEGRATION}

\section{Background}

While TMR offers the potential for markedly improved prosthetic control, the control benefits of the technique can only be realized if the prosthetic is actually used. While this seems to be an obvious prerequisite, at least $35 \%$ of upper limb amputees completely abandon use of their prostheses due to socketrelated limitations or discomfort ${ }^{[54]}$. Lower limb amputees use their prostheses more consistently, but frequently must endure pain or soft tissue problems to maintain their mobility. In addition, a substantial cohort of patients with limb loss have residual limbs that are too short to be candidates for a conventional, socket-based prosthesis. Even in limbs sufficiently long enough to be fit with a socket, the cylindrical shape of most transhumeral and transfemoral amputations presents challenges with regard to suspension and rotation control that plague conventional liner and socket systems. The additional support straps or harnesses required to adequately support the device further limit range of motion and impart additional difficulty with donning and doffing of the prosthetic. Likewise, efforts to overcome the intrinsic design flaw of socket-based strategies frequently employ closed suction environments and/or occlusive liners that predispose to irritation, breakdown, and soft tissue infection ${ }^{[55]}$.

Direct skeletal attachment of extremity prostheses through OI of a percutaneous implant offers a means to circumvent the limitations imposed by the conventional liner and socket fitting strategy [Figure 5]. OI obviates the need to bear weight or control the prosthetic device through a soft tissue intermediary. This translates into enhanced suspension, finer control, greater ease of use, reduced energy expenditure, and increased range of motion in the immediate proximal joint ${ }^{[56-58]}$.

In addition, OI offers a pathway to successful prosthetic use even in the setting of an insufficient soft tissue envelope or skeletal length that precludes fitting of a socket. In this way, OI expands the reconstructive possibilities and maximizes rehabilitative potential following limb loss.

OI of percutaneous implants for attachment of major limb prostheses has been in limited clinical use for nearly 30 years. The concept of placing titanium implants into living bone was first introduced by Bothe et al. ${ }^{[59]}$ in 1940. However, the clinical potential of implanted titanium was not fully realized until Per Ingvar Branemark made the serendipitous discovery of bony in-growth while using titanium chambers to study bone microcirculation in a rabbit model ${ }^{[60]}$. The process, which Branemark described as "osseointegration", served as the foundation for use of titanium implants in dental restoration. OI was first adapted for use in major limb amputees by Rickard Branemark, an orthopedic surgeon and the son of Per Ingvar Branemark, with the first procedure performed in a bilateral transfemoral amputee in $1990^{[61]}$. Leveraging 

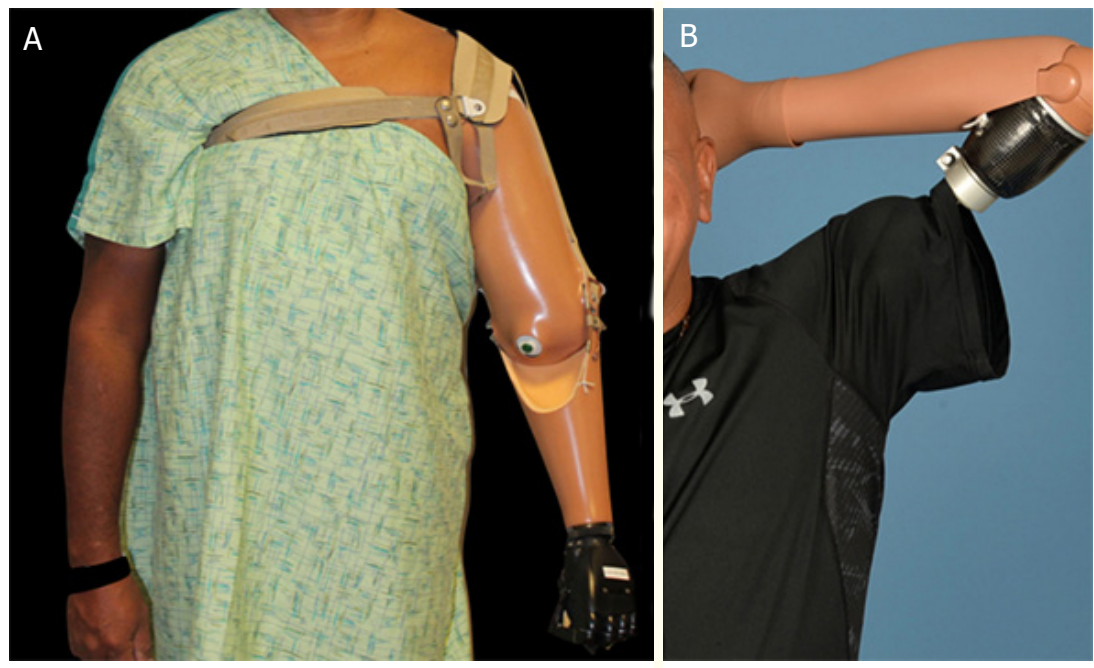

Figure 5. Pre (A) and post (B) osseointegration demonstrating the improved range of motion and absence of need for suspension straps

experience from several hundred procedures, Branemark has worked to standardize the implant system, surgical technique, and rehabilitation protocol with a program entitled Osseointegrated Prostheses for the Rehabilitation of Amputees (OPRA, Integrum AB). Standardized OPRA protocols are now available for femur, humerus, forearm, and thumb amputees ${ }^{[61]}$. The growing interest in OI is demonstrated by the numerous different osseointegrated implants currently in development or clinical use in multiple centers throughout the world. The Compress Transcutaneous Implant (CTI; Zimmer Biomet), Integral Leg Prosthesis (IPL; OrthoDynamics GmbH), and Osseointegrated Prosthetic Limb (OPL; OrthoDynamics) have all been used in persons with transfemoral and transhumeral amputations ${ }^{[62]}$.

\section{Safety}

Concerns related to infection at the skin penetration site remain the single greatest barrier to widespread adoption of the technique. While circumventing the soft tissue issues produced by weight bearing or controlling a prosthetic through a soft tissue intermediary, percutaneous placement of a permanent implant creates a host of new challenges. The soft tissues of a residual limb are significantly thicker and more mobile than those found in the mouth or head and neck, where OI has previously been employed successfully. The relative motion between the abutment (percutaneous component) and the surrounding soft tissues concentrates stress at the skin-implant interface, leading to inflammation, tissue breakdown, fluid generation (e.g., drainage), and potential infection ${ }^{[63]}$. Additionally, extremity soft tissues are less well vascularized than the intraoral and facial tissues where OI has previously been successful. The rates of superficial soft tissue infection following extremity OI have been reported to be as high as $30 \%-66 \%{ }^{[64-67]}$. However, most superficial infections are successfully treated with oral antibiotic therapy, with a 10-year cumulative risk of deep infection leading to implant extraction reported as less than $10 \%{ }^{[68]}$.

\section{Technical details}

While surgical technique varies between implant systems and OI centers, growing experience has identified a universal need to limit the thickness and redundancy of the surrounding soft tissue, in order to minimize motion at the skin penetration site. In the two-stage OPRA procedure, the soft tissues are thinned to the thickness of a full-thickness skin graft, which is affixed to the cortical bone surrounding the percutaneous abutment. In single-stage OPL, IPL, and CTI procedures, the vascularity of the surrounding tissues are preserved to a much greater extent, but the adjacent soft tissue flap is thinned at least to the level of scarpa's fascia. These soft tissue management strategies were born out of clinical experience that saw revision surgery for soft tissue redundancy or hypergranulation exceed the need to return to the operating room 
for infection-related concerns ${ }^{[69]}$. As the cumulative experience with OI expands and the natural history of the skin penetration site becomes better delineated, the technique for implant placement and soft tissue manipulation is sure to evolve.

\section{Future directions}

Current research efforts aim to improve the safety of OI, while also leveraging the percutaneous abutment as a conduit for prosthetic feedback and control. While OI has been successfully used in the extremity, in the absence of a seal between the implant and surrounding soft tissue, soft tissue integration would dramatically decrease the risk for infection and ameliorate the chronic inflammation currently experienced at the implant interface [Figure 6]. Efforts are currently underway to use bioprinting and tissue engineering to generate a dynamic dermal seal. From the standpoint of neuromuscular integration, the osseintegrated implant and percutaneous abutment serve as a convenient channel through which to directly connect implantable sensors with the prosthetic. Direct connectivity dramatically increases the clinical potential offered by feedback and control strategies that are currently hampered by the need for surface detection, such as regenerative peripheral nerve or agonist-antagonist myoneural interfaces. The enhanced OPRA (e-OPRA), which utilizes a modified abutment screw to allow passage of transcortical wires between implantable electrodes and the terminal device, is already in clinical use in Europe $\mathrm{e}^{[70]}$.

\section{EXTREMITY VASCULARIZED COMPOSITE ALLOTRANSPLANTATION}

\section{Background}

Joseph Murray, an American plastic surgeon, performed the first kidney transplant in the world in 1954 at the Peter Bent Brigham Hospital in Boston, Massachusetts ${ }^{[7]}$. A decade later, the first hand transplantation was performed in Ecuador ${ }^{[72]}$. However, the patient suffered from irreversible rejection and the graft was explanted three weeks later ${ }^{[72]}$. The second hand transplantation was performed in Lyon, France in 1998 but eventually failed due to noncompliance with immunosuppression regimen ${ }^{[73]}$. Although unsuccessful, this case demonstrated the feasibility of the procedure and the importance of compliance/postoperative care. This was followed in January 1999 by the first hand transplantation in the United States, in Louisville, Kentucky $^{[73,74]}$.

The field of extremity VCA quickly gained popularity as replantation data suggested better functional outcomes when compared with revision amputation and prosthetic fitting ${ }^{[75]}$. By 2009, 53 successful hand transplants had been performed worldwide ${ }^{[76]}$. Now, roughly 150 upper limb transplantations in 100 patients have been performed to date at 45 centers worldwide, including those in United States, France, China, Austria, Italy, Spain, Belgium, Poland, Mexico, and Australia ${ }^{[76-85]}$. In 2015, the world's first pediatric bilateral hand-forearm transplantation and, in 2016, the first transatlantic hand transplantation were performed at the University of Pennsylvania under the direction of the senior author (Levin LS) ${ }^{[78,86]}$.

Although it has been advocated as a reasonable pursuit, successful VCA for lower limb amputees have not been reported to date ${ }^{[8]]}$. This is mainly due to the fact that, when compared to prosthetic options, the risks, including those associated with surgery and lifelong immunosuppression, outweigh potential benefits. For this reason, the presented discussion on VCA is limited to upper extremity.

Hand and upper-limb transplantation represents the most commonly performed surgery in the growing field of $\mathrm{VCA}^{[88,89]}$. The hand transplantation process consists of patient selection, preoperative evaluation/ preparation including cadaveric practice runs, the procurement and transplantation procedure, immunosuppression maintenance, and postoperative rehabilitation and follow-up ${ }^{[8,90]}$. Significant progress has been made in the past several decades in extremity VCA, including $3 \mathrm{D}$ printing, novel implants, improved imaging techniques [e.g., functional magnetic resonance imaging (MRI)], immunosuppressive regimens, and efficiency of surgical technique ${ }^{[88]}$. 

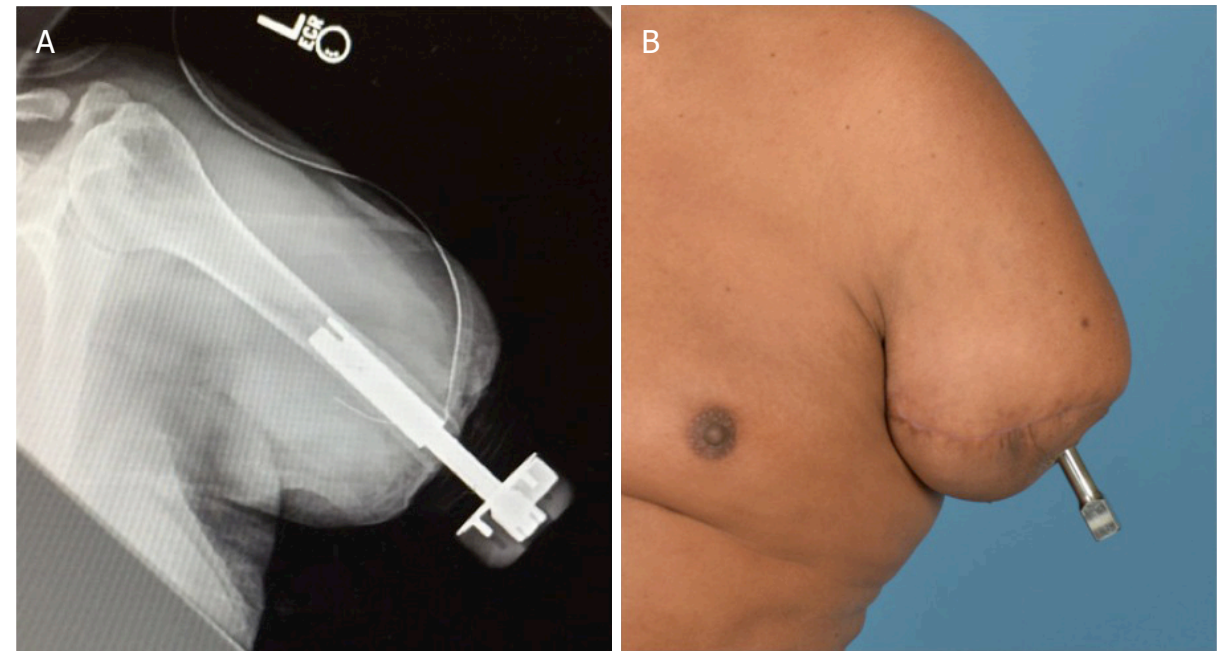

Figure 6. Osseointegration radiograph (A) and skin penetration site (B)

Upper extremity VCA faces controversies and challenges that unfold alongside the procedure itself. Policy and regulatory issues strongly influence progress of the field, so much so that transplantation is being performed at overseas centers as part of clinical trials rather than a standard treatment option ${ }^{[9]}$. Preoperatively, patients should be counseled regarding realistic expectations including functional, sensory, and aesthetic ones ${ }^{[92]}$.

\section{Indications and patient selection}

A survey of North American hand surgeons indicates that most support upper extremity VCA for bilateral or dominant below-elbow amputees ${ }^{[93]}$. Specific clinical selection criteria and contraindications developed by the American Society for Reconstructive Transplantation can only be expected to change with maturation of the field and growing reports of functional outcomes with longer follow-up periods ${ }^{[89,93]}$. Patient evaluation is exhaustive and factors including motivation, comorbidities, social support, and psychological profile are critical when deciding if and when to proceed ${ }^{[14]}$. The process involves transplant physician/surgeons, social workers, psychiatrists, and rehabilitative specialists. Upper extremity VCA is most frequently performed for forearm and wrist-level amputations, although above-elbow results are promising and those patients are able to perform many activities of daily living ${ }^{[94]}$. In more distal amputations, extrinsic hand function is possible even without nerve regeneration given the presence of muscles and tendons. More distally, intrinsic hand function and sensation can be restored more quickly given the shorter distances necessary for nerve regeneration.

At our institution, the recipient should be HIV-negative, without any coexisting psychosocial or medical issues, and with a negative cross-match with the donor. Female patients must have a negative pregnancy test. In general, patients should be between the ages of 18 and 65 years old. In fact, just several years ago, it was proposed that VCA should not be extended to pediatric patients given the number of unknowns ${ }^{[95]}$. However, in July 2015, we performed a bilateral hand transplantation on an eight-year old prior kidney transplant recipient with excellent results at four-year follow-up (unpublished data) ${ }^{[78]}$.

\section{Pediatric hand transplantation}

The greater plasticity of the immature brain and longer potential lifetime are potential advantages of VCA in the pediatric patient. Obvious challenges of upper extremity VCA in this young population include informed consent, psychosocial assessment, greater surgical risk in part due to increased technical complexity, lack of assessment tools of objective outcomes, and compliance with rehabilitation/ 
immunosuppression demands ${ }^{[77]}$. Preoperative evaluation of the pediatric patient includes multiple visits with orthopedic/plastic surgery, transplantation medicine, and occupational/physical therapy ${ }^{[78,88]}$. The child's goals for functional independence are the focus of the occupational therapy assessment ${ }^{[77]}$. Psychosocial aspects are assessed by a child psychologist, pediatric transplantation pharmacist, and a social worker. Informed consent must include a discussion with both the patient and parents regarding all possible risks from the surgery while addressing the unknowns.

The consequences of long-term immunomodulation may become more apparent in this group and some remained concerned for potential learning disabilities and growth impairment ${ }^{[95]}$. It is unclear if pediatric patients will have worse rejection episodes or adverse effects of medications when compared with adult patients, although that has not been a concern in our pediatric VCA patient to date. In addition, unpublished data from our institution suggest that hand-forearm growth in the pediatric patient are as you would expect based on replantation literature and normal growth in the non-transplanted pediatric population.

\section{Overseas hand-forearm transplantation}

For the first time in upper extremity VCA history, a successful transatlantic upper extremity VCA was performed at the University of Pennsylvania. Our group was approached by colleagues from Hopital European Georges Pompidoi at Paris Descartes University in 2016 to list a European patient for a bilateral hand transplant. The recipient and donor were separated hundreds of miles between France (country of residence) and the United States (VCA team), respectively. The recipient's preoperative assessment was done in France; however, she was unable to have the transplant in her country due to health-system issues. The director of the University of Pennsylvania program (Levin LS) raised support, including financial, for the endeavor and coordinated the team of $30+$ specialists and surgeons who would be necessary to perform the transplant. Meanwhile, the patient underwent health screening in France and, simultaneously, coordination with the organ procurement organization was performed to enable a match. Our team calculated precise travel scenarios so that, if donor limbs became available, the recipient patient could begin her travels to Philadelphia in time. Appropriate documentation for travel was ensured much in advance of donor limb availability. In August 2016, the director of the hand transplant program received a call that donor hands were available and the patient then immediately embarked on a 700 mile trip to Philadelphia. The surgery proceeded as expected, lasting nine hours. Aside from the need for minor hematoma evacuation on Postoperative Day 17 for bilateral extremities, the recovery was excellent. French surgeons and specialists with extensive VCA experience then assumed her care upon return, and she returned to the University of Pennsylvania for follow-up eight months later. Her motor and sensory exam has been improving [Figure 7]. Since then, another transatlantic hand transplantation was performed, again in a French recipient, without any event. We were happy to have had such an impact on the quality of life of these overseas patients.

\section{Technical considerations}

Checklists are followed closely for all aspects of the operation. In brief, the recipient is prepared first by obtaining peripheral nerve blocks and central venous and large bore intravenous access. General anesthesia is then administered and the residual limbs are dissected under tourniquet control, identifying and tagging all key structures similar to the donor limb preparation. This can be the most difficult part of the operation as tendons, vessels, and nerves are often enveloped in scar tissue. Simultaneously, the donor team is working to prepare and tag vital structures in the transplant extremities. The bones are then prepared with custom cut guides according to the preoperative plan. Once the donor and recipient limbs are fully prepared and structures tagged by the surgical teams, osteosynthesis is performed. Depending on the cold ischemia time and level of transplant, either vascular anastomoses can be performed at this stage or tendon/muscle repairs. We prefer to reperfuse the limbs as soon as possible to limit ischemia-reperfusion injury. This is followed by tendon/muscle repairs and then nerve repairs. Skin closure is performed in a 


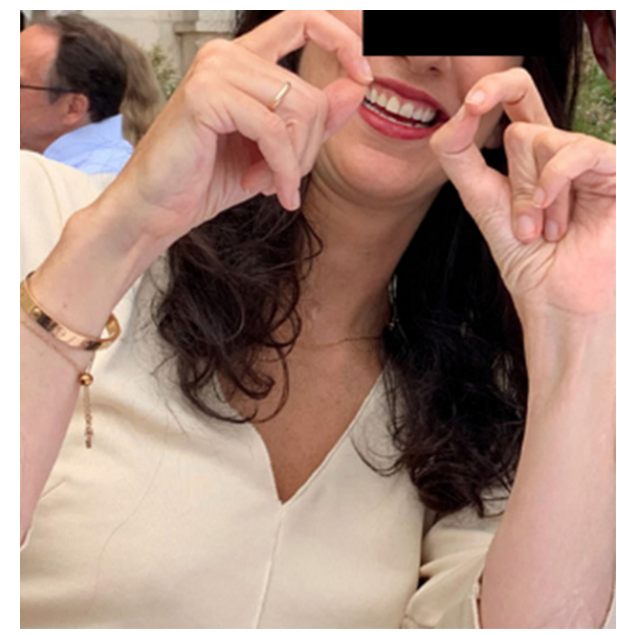

Figure 7. Nearly three-year follow-up of the world's first overseas hand-forearm transplantation

nonconstructive manner. The limbs are photographed, carefully dressed, and splinted. The patient then recovers in the Intensive Care Unit for close monitoring.

\section{Immunosuppressive protocol}

The immunologic profile of hand transplants differs slightly when compared with solid organ transplants due to their composite tissue, including bone, tendon, nerve, muscle, and skin, which is more antigenic ${ }^{[88]}$. That being said, the immunosuppressive therapy is modeled after solid organ transplantation ${ }^{[96]}$. This includes induction therapy of several perioperative doses of polyclonal/monoclonal antibodies such as thymoglobulin along with IV steroids. Maintenance therapy consists of a multidrug regimen of tacrolimus (calicineurin inhibitor), mycophenolate mofetil, and prednisone ${ }^{[16]}$. Alterations to this standard in an attempt to reduce acute rejection episodes have been investigated and applied, including steroid withdrawal, conversion to mammalian target of rapamycin (mTOR) inhibitor sirolimus from tacrolimus, the use of topical steroids, and Belatacept (selective T-cell costimulation blocker) ${ }^{[79,97-100]}$. Switching tacrolimus to sirolimus has been done because of increased creatinine values, resulting in normalization of levels ${ }^{[99]}$. Immunomodulation strategies to create a state of immunologic chimerism in the recipient, such as infusion of donor-derived bone marrow stem cells as part of induction therapy, have been shown to be safe, welltolerated, and allow for low-dose tacrolimus monotherapy ${ }^{[101]}$. Furthermore, delivery of rapamycin has been shown to promote immunoregulation and survival of the $\mathrm{VCA}^{[102]}$.

Consequences of prolonged immunosuppression include opportunistic infections, and medication side effects such as metabolic disorders, nephrotoxicity, neurotoxicity, avascular necrosis, and wound healing issues related to steroid use and neoplasms (e.g., cutaneous and lymphoproliferative disorders). The future of hand transplantation will depend on minimizing side effects of immunosuppression, or perhaps even more ambitious, achieving donor-specific immunologic tolerance and rejection-free maintenance without the use of immunosuppression. Prophylaxis therapy includes antibiotics for 10 days, trimethoprim/sulfamethaxoazole to prevent Pneumocystis carinii pneumonia, and valganciclovir to prevent cytomegalovirus infection/reactivation for six months ${ }^{[99]}$.

\section{Postoperative course}

Standardized vigilant follow-up is paramount to monitor for signs of surgical complications, acute/chronic rejection, and untoward effects of immunosuppression. This becomes even more critical with the growing transatlantic cases, which require follow-up with a treatment team with expertise in VCA in the area of residence in addition to follow-up with the team that performed and is familiar with the transplant. At six 
weeks postoperatively, the patient typically may return to their home residence. We have used FaceTime, Skype, and other Internet-based video platforms to communicate internationally on an as needed basis. In-person visits are coordinated between the patient and the treatment team at the center involved in the transplant and occur every 2-3 months during the first year and every 6-12 months thereafter ${ }^{[88]}$.

Although superficial (e.g., skin) detection of rejection is more easily accomplished than that of deeper structures, the clinical signs of skin rejection are nonspecific. These include findings such as edema, erythema, erythematous maculopapular rash, hair loss, and desquamation at the fingers ${ }^{[80,103]}$. Deep biopsies are rarely performed to diagnose rejection, but one may see lymphocytic infiltrates. Chronic rejection findings are nonspecific, but involve vessel intimal hyperplasia ${ }^{[104-106]}$. Our protocol includes weekly skin biopsies and laboratory tests (renal function, immunosuppression drug concentrations, and complete blood counts) for the first month and subsequent tapering depending on the stability of the drug levels and allograft.

Outcomes following VCA are highly dependent on rehabilitation, which is extensive and can last 2-4 years to optimize cortical reintegration of the transplanted extremity ${ }^{[107]}$. Rehabilitation typically begins anywhere from $12 \mathrm{~h}$ to three days after surgery depending on the transplant surgeon preference and is extensive, with physiotherapy, electrostimulation, and occupational therapy components ${ }^{[8,99]}$. Physical therapy exercises include edema management, gentle range of motion exercises, and custom orthosis management. Different splints are used to protect the grafts, avoid retraction, and facilitate the right position of each hand part after extensor and flexor tendon balance. Therapy is extensive during the first year and is usually $4-5 \mathrm{~h}$, five days a week. This regimen is gradually tapered depending on the level of transplant and needs of the patient $^{[108]}$.

Rehabilitation for the pediatric transplant recipient was more difficult due to their attention span, motivations, and emotions. Therapy began six days after transplantation and continued daily for five weeks in acute care, then two weeks in inpatient rehabilitation, followed by ongoing/school therapy. Time for patient-caregiver bonding, child life activities, and rest was set-aside during the therapy days and is as important as the therapy itself. At seven weeks, the patient transitioned to a day hospital program in his community where he received therapy and schooling for five days per week, and then transitioned to outpatient therapy. Therapy is ongoing at four years post-surgery and the exact duration necessary continues to be an area of investigation. Our therapists suggest continuing therapy and minimizing compensatory motor strategies for two years following plateau of sensorimotor function and cortical plasticity. Additional procedures may be necessary during the course of follow-up and this should be discussed preoperatively. These include cosmetic revisions, hardware removal, tendon transfers, and tendon shortening ${ }^{[99]}$.

\section{VCA outcomes}

Standardizing outcome measures remains a challenge for extremity VCA given the variety of surgical protocols, host risk factors, immunosuppressive regimens, and transplant patient/level heterogeneity ${ }^{[88]}$. Moreover, measures and definitions of success are variable. When considering the pediatric patient, there are no validated outcomes measured for hand function. For the adult patients at our transplant center, functional outcome measures include the Sollerman test, a standardized measure of manual dexterity for motor functions; the Disabilities of the Arm, Shoulder and Hand questionnaire; and the Hand Transplant Scoring System ${ }^{[109]}$. We utilized the two-point discrimination test and Semmes-Weinstein monofilament tests for sensation ${ }^{[108]}$. For our pediatric transplant recipient, we used the box and block and nine-hole peg tests that elucidate progress at the functional activity level and efficiency of upper extremity gross motor skills compared with baseline ${ }^{[88]}$. We also used the Functional Independence Measure for Children to assess ability to perform daily activities of living ${ }^{[88]}$. 
Structural brain MRI and magnetoencephalography to record neural correlates of sensory responses and hand movement, motor cortex mapping with transcranial magnetic stimulation and motor evoked potentials from intrinsic muscles, and functional MRI (fMRI) before and after transplantation are used to track progress. Psychological and social assessments are made through semi-structured interviews to support coping with transplantation and rehabilitation.

Reported outcomes following hand-forearm transplantation have been promising and follow-up now extends over a decade ${ }^{[82,99]}$. It is well known that more proximal amputations fair poorer with transplantation when compared to distal ones given the distance for regeneration. However, continual yearly improvement is seen in the majority of patients ${ }^{[92]}$. An international registry observed that all transplant recipients develop protective sensibility against pain, $90 \%$ regained tactile sensibility, $82.3 \%$ achieved discriminative fine sensibility, and $75 \%$ reported overall improved quality of life ${ }^{[16]}$. A review of five recipients of bilateral hand allotransplantation performed in Lyon France (Follow-up 3-13 years) demonstrated $100 \%$ patient and graft survival, adequate sensorimotor recovery (protective/tactile sensitivity), an ability to perform the majority of daily living activities (e.g., eating, shaving, and using the telephone), and normal social lives ${ }^{[99]}$. In fact, a return of sensation, albeit to varying degrees and timing, can generally be expected in upper extremity VCA patients. Follow-up has also demonstrated normal appearance (i.e., color, temperature, texture, and hair and nail growth) and uneventful bone healing, with normal structure of the recipient and transplanted bones. Motion recovery started at 3-6 months for these patients, with extrinsic recovery allowing the patients to grasp large objects, whereas the intrinsic activity started later (9-12 months), increasing in the first fiveyears post-transplant. Patients experienced at least one episode of acute rejections (range 1-6) ${ }^{[99]}$. The Louisville group reported intrinsic function recovery after at least two years of followup in three of five patients ${ }^{[10]}$. The Innsbruck group recently reported on an 18-year experience, with outcomes demonstrating improvement in hand function and sensibility in the first five years and stability thereafter ${ }^{[100]}$. This same group also reported that one of the five patients, a unilateral hand transplant recipient, suffered from recurrent and unmanageable antibody mediated rejections, which eventually led to chronic rejection vasculopathy, necessitating amputation seven years postoperatively. Although bias cannot be excluded based on inherent differences in patient populations, a comparison of prosthetic and upper extremity transplant recipients noted improved quality of life in the transplanted group ${ }^{[11]}$.

Aside from wound healing complications, risks of upper extremity VCA include vessel thrombosis, rejection and possible graft loss, hematoma, and deep venous thrombosis. Aside from side effects of immunosuppression, medication side effects include neurotoxicity and nephrotoxicity. Although graft loss was reported in $22.4 \%$ of patients in a 2015 review, graft loss may be estimated at $<1 \%$ in patients who are compliant with medications ${ }^{[112]}$. Combined vascularized composite allotransplantation of multiple anatomic areas (e.g., face and hand) has demonstrated an unacceptably high risk of complications, including graft loss and death ${ }^{[92]}$. It is estimated that up to $85 \%$ of hand transplant recipients may experience acute rejection within the first year, which manifests as cutaneous lesions ${ }^{[16,113]}$. Acute rejection is typically reversed successfully with intravenous steroids or increasing oral steroid dose. Other complications included transient hyperglycemia, renal toxicity related to immunosuppressive drugs, osteopenia, and infectious complications. Vascular thrombosis, when it occurs, may be successfully treated with embolectomy and bypass procedures. To our knowledge, there have been no reported cases of malignancies ${ }^{[99,100]}$.

\section{CONCLUSION}

OI, TMR, and VCA are just a few ways by which our reconstructive ladder is changing. With regards to prosthetic technology, amputees continue to experience high levels of disability, distress, dependency, and overall dissatisfaction. Bionic limbs still do not replicate the complex function of the upper extremity muscles. It is important to recognize that amputation does not necessarily denote failure, but we have 
to find ways to provide these patients with means for obtaining better satisfaction and quality of life postoperatively. Despite the advances in VCA over the last 20 years, there are many challenges that face this discipline including indications for patient selection, minimizing immunosuppressive regimens, standardizing outcome measures, and establishing reliable protocols for monitoring, diagnosing, and managing rejection. The question remains if the risks associated with lifelong immunosuppression justify the non-lifesaving operation. Continued discussions of the advances, successes, and failures well determine how rapidly we are able to improve upon the aforementioned reconstructive options.

\section{DECLARATIONS}

\section{Acknowledgments}

The Authors thank Hansjörg Wyss Foundation for their support.

\section{Authors' contributions}

Made substantial contributions to conception and design of the study and performed data analysis and interpretation: Azoury SC, Bauder A, Souza JM, Stranix JT, Othman S, McAndrew C, Tintle SM, Kovach SJ, Levin LS

Performed data acquisition, provided administrative, technical, and material support: Azoury SC, Bauder A, Souza JM, Stranix JT, Othman S, McAndrew C, Tintle SM, Kovach SJ, Levin LS

Reviewed the manuscript for content and grammar/spelling mistakes: Azoury SC, Bauder A, Souza JM, Stranix JT, Othman S, McAndrew C, Tintle SM, Kovach SJ, Levin LS

\section{Availability of data and materials}

Not applicable.

\section{Financial support and sponsorship}

None.

\section{Conflicts of interest}

All authors declared that there are no conflicts of interest.

\section{Ethical approval and consent to participate}

Not applicable.

\section{Consent for publication}

Not applicable.

\section{Copyright}

(c) The Author(s) 2020.

\section{REFERENCES}

1. Levin LS. The reconstructive ladder. An orthoplastic approach. Orthop Clin North Am 1993;24:393-409.

2. Azoury SC, Stranix JT, Kovach SJ, Levin LS. Principles of orthoplastic surgery for lower extremity reconstruction: why is this important? J Reconstr Microsurg 2019; Epub ahead of print [PMID: 31454835 DOI: 10.1055/s-0039-1695753]

3. Janis JE, Kwon RK, Attinger CE. The new reconstructive ladder: modifications to the traditional model. Plast Reconstr Surg 2011;127:205-12S.

4. Mathes SJ, Nahai F. Classification of the vascular anatomy of muscles: experimental and clinical correlation. Plast Reconstr Surg 1981;67:177-87.

5. Gottlieb LJ, Krieger LM. From the reconstructive ladder to the reconstructive elevator. Plast Reconstr Surg 1994;93:1503-4.

6. Wong CJ, Niranjan N. Reconstructive stages as an alternative to the reconstructive ladder. Plast Reconstr Surg 2008;121:362-3e. 
7. Erba P, Ogawa R, Vyas R, Orgill DP. The reconstructive matrix: a new paradigm in reconstructive plastic surgery. Plast Reconstr Surg 2010;126:492-8.

8. Zuo KJ, Willand MP, Ho ES, Ramdial S, Borschel GH. Targeted muscle reinnervation. Plast Reconstr Surg 2018;141:1447-58.

9. Fracol ME, Janes LE, Ko JH, Dumanian GA. Targeted muscle reinnervation in the lower leg. Plast Reconstr Surg 2018;142:541-50e.

10. Dumanian G, Souza J. Surgical techniques for targeted muscle reinnervation. 2013. pp. 21-44.

11. Tintle SM, LeBrun C, Ficke JR, Potter BK. What is new in trauma-related amputations. J Orthop Trauma 2016;30:S16-20.

12. Hebert JS, Rehani M, Stiegelmar R. Osseointegration for lower-limb amputation: a systematic review of clinical outcomes. JBJS Rev 2017;5:e10.

13. Brånemark RP, Hagberg K, Kulbacka-Ortiz K, Berlin Ö, Rydevik B. Osseointegrated percutaneous prosthetic system for the treatment of patients with transfemoral amputation. J Am Acad Orthop Surg 2019;27:e743-51.

14. Levin LS. From autotransplantation to allotransplantation: a perspective on the future of reconstructive microsurgery. J Reconstr Microsurg 2018;34:681-2.

15. Carlsen BT, Prigge P, Peterson J. Upper extremity limb loss: functional restoration from prosthesis and targeted reinnervation to transplantation. J Hand Ther 2014;27:106-14.

16. Petruzzo P, Dubernard JM. The international registry on hand and composite tissue. Clin Transpl 2011;247-53.

17. Kuiken TA, Li G, Lock BA, Lipschutz RD, Miller LA, et al. Targeted muscle reinnervation for real-time myoelectric control of multifunction artificial arms. JAMA 2009;301:619-28.

18. Souza JM, Cheesborough JE, Ko JH, Cho MS, Kuiken TA, et al. Targeted muscle reinnervation: a novel approach to postamputation neuroma pain. Clin Orthop Relat Res 2014;472:2984-90.

19. Cheesborough JE, Souza JM, Dumanian GA, Bueno RA. Targeted muscle reinnervation in the initial management of traumatic upper extremity amputation injury. Hand 2014;9:253-7.

20. Miranda RA, Casebeer WD, Hein AM, Judy JW, Krotkov EP, et al. DARPA-funded efforts in the development of novel brain-computer interface technologies. J Neurosci Methods 2014;244:52-67.

21. Mioton LM, Dumanian GA. Targeted muscle reinnervation and prosthetic rehabilitation after limb loss. J Surg Oncol 2018;118:807-14.

22. Bowen JB, Wee CE, Kalik J, Valerio IL. Targeted muscle reinnervation to improve pain, prosthetic tolerance, and bioprosthetic outcomes in the amputee. Adv Wound Care 2017;6:261-7.

23. Atzori M, Müller H. Control capabilities of myoelectric robotic prostheses by hand amputees: a scientific research and market overview. Front Syst Neurosci 2015;9:162.

24. Hargrove LJ, Miller LA, Turner K, Kuiken TA. Myoelectric pattern recognition outperforms direct control for transhumeral amputees with targeted muscle reinnervation: a randomized clinical trial. Sci Rep 2017;7:13840.

25. Kuiken TA, Miller LA, Turner K, Hargrove LJ. A comparison of pattern recognition control and direct control of a multiple degree-offreedom transradial prosthesis. IEEE J Transl Eng Heal Med 2016;4:2100508.

26. Gart MS, Souza JM, Dumanian GA. Targeted muscle reinnervation in the upper extremity amputee: a technical roadmap. J Hand Surg Am 2015:40:1877-88.

27. Pierrie SN, Gaston RG, Loeffler BJ. Targeted muscle reinnervation for prosthesis optimization and neuroma management in the setting of transradial amputation. J Hand Surg Am 2019;44:525.e1-525.e8.

28. Morgan EN, Potter BK, Souza JM, Tintle SM, Nanos GP. Targeted muscle reinnervation for transradial amputation: description of operative technique. Tech Hand Up Extrem Surg 2016;20:166-71.

29. Ortiz-Catalan M, Håkansson B, Brånemark R. An osseointegrated human-machine gateway for long-term sensory feedback and motor control of artificial limbs. Sci Transl Med 2014;6:257re6.

30. Takagi T, Ogiri Y, Kato R, Kodama M, Yamanoi Y, et al. Selective motor fascicle transfer and neural-machine interface: case report. J Neurosurg 2019;1-7.

31. Gaston RG, Bracey JW, Tait MA, Loeffler BJ. A novel muscle transfer for independent digital control of a myoelectric prosthesis: the starfish procedure. J Hand Surg Am 2019;44:163.e1-163.e5.

32. Pasquina PF, Perry BN, Miller ME, Ling GSF, Tsao JW. Practice recent advances in bioelectric prostheses. Neurol Clin Pract 2015;5:164-70.

33. Hargrove LJ, Simon AM, Young AJ, Lipschutz RD, Finucane SB, et al. Robotic leg control with EMG decoding in an amputee with nerve transfers. N Engl J Med 2013;369:1237-42.

34. Hargrove LJ, Young AJ, Simon AM, Fey NP, Lipschutz RD, et al. Intuitive control of a powered prosthetic leg during ambulation: a randomized clinical trial. JAMA 2015;313:2244-52.

35. Lund LH, Benson L. Real-time myoelectric control of knee and ankle motions for transfemoral amputees. JAMA 2011;305:1542-4.

36. Pet MA, Ko JH, Friedly JL, Smith DG. Traction neurectomy for treatment of painful residual limb neuroma in lower extremity amputees. J Orthop Trauma 2015;29:e321-5.

37. Suckow BD, Goodney PP, Nolan BW, Veeraswamy RK, Gallagher P, et al. Domains that determine quality of life in vascular amputees. Ann Vasc Surg 2015;29:722-30.

38. Kuffler DP. Coping with phantom limb pain. Mol Neurobiol 2018;55:70-84.

39. Ephraim PL, Wegener ST, MacKenzie EJ, Dillingham TR, Pezzin LE. Phantom pain, residual limb pain, and back pain in amputees: results of a national survey. Arch Phys Med Rehabil 2005;86:1910-9.

40. Richardson C, Glenn S, Nurmikko T, Horgan M, Fe C. Incidence of phantom phenomena including phantom limb pain 6 months after major lower limb amputation in patients with peripheral vascular disease. Clin J Pain 2006;22:353-8.

41. Ducic I, Mesbahi AN, Attinger CE, Graw K. The role of peripheral nerve surgery in the treatment of chronic pain associated with 
amputation stumps. Plast Reconstr Surg 2008;121:908-14.

42. Poyntz SA, Dalal M, Hacking N, Fowler S. Peripheral interventions for painful stump neuromas of the lower limb: a systematic review. Clin J Pain 2017;34:285-95.

43. Ives GC, Kung TA, Nghiem BT, Ursu DC, Brown DL, et al. Current state of the surgical treatment of terminal neuromas. Clin Neurosurg 2018;83:354-64.

44. Pet MA, Ko JH, Friedly JL, Mourad PD, Smith DG. Does targeted nerve implantation reduce neuroma pain in amputees? Clin Orthop Relat Res 2014;472:2991-3001.

45. Dumanian GA, Potter BK, Mioton LM, Ko JH, Cheesborough JE, et al. Targeted muscle reinnervation treats neuroma and phantom pain in major limb amputees: a randomized clinical trial. Ann Surg 2019;270:238-46.

46. Agnew SP, Schultz AE, Dumanian GA, Kuiken TA. Targeted reinnervation in the transfemoral amputee: a preliminary study of surgical technique. Plast Reconstr Surg 2012;129:187-94.

47. Fracol ME, Janes LE, Ko JH, Dumanian GA. Targeted muscle reinnervation in the lower leg: an anatomical study. Plast Reconstr Surg 2018; $142: 541-50 \mathrm{e}$

48. Curtin C. Pain examination and diagnosis. Hand Clin 2016;32:21-6.

49. Eberlin KR, Ducic I. Surgical algorithm for neuroma management: a changing treatment paradigm. Plast Reconstr Surg Glob Open 2018;6:e1952.

50. Poppler LH, Parikh RP, Bichanich MJ, Rebehn K, Bettlach CR, et al. Surgical interventions for the treatment of painful neuroma: a comparative meta-analysis. Pain 2018;159:214-23.

51. Kubiak CA, Kemp SWP, Cederna PS. Regenerative peripheral nerve interface for management of postamputation neuroma. JAMA Surg 2018;153:681-2.

52. Kung TA, Langhals NB, Martin DC, Johnson PJ, Cederna PS, et al. Regenerative peripheral nerve interface viability and signal transduction with an implanted electrode. Plast Reconstr Surg 2014;133:1380-94.

53. Frost CM, Ursu DC, Flattery SM, Nedic A, Hassett CA, et al. Regenerative peripheral nerve interfaces for real-time, proportional control of a neuroprosthetic hand. J Neuroeng Rehabil 2018;15:108.

54. Biddiss E, Chau T. Upper limb prosthesis use and abandonment: a survey of the last 25 years. Prosthet Orthot Int 2007;31:236-57.

55. Paternò L, Ibrahimi M, Gruppioni E, Menciassi A, Ricotti L. Sockets for limb prostheses: a review of existing technologies and open challenges. IEEE Trans Biomed Eng 2018;65:1996-2010.

56. Hagberg K, Häggström E, Uden M, Brånemark R. Socket versus bone-anchored trans-femoral prostheses: hip range of motion and sitting comfort. Prosthet Orthot Int 2005;29:153-63.

57. Tranberg R, Zügner R, Kärrholm J. Improvements in hip- and pelvic motion for patients with osseointegrated trans-femoral prostheses. Gait Posture 2011;33:165-8.

58. Van De Meent H, Hopman MT, Frölke JP. Walking ability and quality of life in subjects with transfemoral amputation: a comparison of osseointegration with socket prostheses. Arch Phys Med Rehabil 2013;94:2174-8.

59. Bothe, RT, Beaton, KE, Davenport H. Reaction of bone to multiple metallic implants. Surg Gynecol Obs 1940;71:598-602.

60. Branemark PI. Osseointegration and its experimental background. J Prosthet Dent 1983;50:399-410.

61. Li Y, Brånemark R. Osseointegrated prostheses for rehabilitation following amputation. Unfallchirurg 2017;120:285-92.

62. Zaid MB, O’Donnell RJ, Potter BK, Forsberg JA. Orthopaedic osseointegration: state of the art. J Am Acad Orthop Surg 2019;27:e977-85.

63. Yerneni S, Dhaher Y, Kuiken TA. A computational model for stress reduction at the skin-implant interface of osseointegrated prostheses. J Biomed Mater Res A 2012;100:911-7.

64. Al Muderis M, Lu W, Tetsworth K, Bosley B, Li JJ. Single-stage osseointegrated reconstruction and rehabilitation of lower limb amputees: The Osseointegration Group of Australia Accelerated Protocol-2 (OGAAP-2) for a prospective cohort study. BMJ Open 2017;7:e13508.

65. Aschoff HH, Kennon RE, Keggi JM, Rubin LE. Transcutaneous, distal femoral, intramedullary attachment for above-the-knee prostheses: an endo-exo device. J Bone Joint Surg Am 2010;92:180-6.

66. Muderis MA, Khemka A, Lord SJ, Van De Meent H, Frolke JPM. Safety of osseointegrated implants for transfemoral amputees: a twocenter prospective cohort study. J Bone Joint Surg Am 2016;98:900-9.

67. Brånemark R, Berlin Ö, Hagberg K, Bergh P, Gunterberg B, et al. A novel osseointegrated percutaneous prosthetic system for the treatment of patients with transfemoral amputation: a prospective study of 51 patients. Bone Joint J 2014;96-B:106-13.

68. Tillander J, Hagberg K, Berlin Ö, Hagberg L, Brånemark R. Osteomyelitis risk in patients with transfemoral amputations treated with osseointegration prostheses. Clin Orthop Relat Res 2017;475:3100-08.

69. Atallah R, Leijendekkers RA, Hoogeboom TJ, Frölke JP. Complications of bone-anchored prostheses for individuals with an extremity amputation: a systematic review. PLoS One 2018;13:e0201821.

70. Mastinu E, Doguet P, Botquin Y, Hakansson B, Ortiz-Catalan M. Embedded system for prosthetic control using implanted neuromuscular interfaces accessed via an osseointegrated implant. IEEE Trans Biomed Circuits Syst 2017;11:867-77.

71. Delmonico FL. Interview with Dr Joseph Murray. Am J Transplant 2002;2:803-6.

72. Fernandez JJG, Febres-Cordero RG, Simpson RL. The untold story of the first hand transplant: dedicated to the memory of one of the great minds of the ecuadorian medical community and the world. J Reconstr Microsurg 2019;35:163-7.

73. Dubernard JM, Owen E, Herzberg G, Lanzetta M, Martin X, et al. Human hand allograft: report on first 6 months. Lancet 1999;353:1315-20.

74. Breidenbach WC, Gonzales NR, Kaufman CL, Klapheke M, Tobin GR, et al. Outcomes of the first 2 American hand transplants at 8 and 6 years posttransplant. J Hand Surg Am 2008;33:1039-47. 
75. Graham B, Adkins P, Tsai TM, Firrell J, Breidenbach WC. Major replantation versus revision amputation and prosthetic fitting in the upper extremity: a late functional outcomes study. J Hand Surg Am 1998;23:783-91.

76. Thuong M, Petruzzo P, Landin L, Mahillo B, Kay S, et al. Vascularized composite allotransplantation - a Council of Europe position paper. Transpl Int 2019;32:233-40.

77. Amaral S, Scott Levin L. Pediatric and congenital hand transplantation. Curr Opin Organ Transplant 2017;22:477-83.

78. Amaral S, Kessler SK, Levy TJ, Gaetz W, McAndrew C, et al. 18-month outcomes of heterologous bilateral hand transplantation in a child: a case report. Lancet Child Adolesc Heal 2017;1:35-44.

79. Shores JT, Imbriglia JE, Lee WPA. The current state of hand transplantation. J Hand Surg Am 2011;36:1862-7.

80. Shores JT, Malek V, Lee WPA, Brandacher G. Outcomes after hand and upper extremity transplantation. J Mater Sci Mater Med 2017;28:72.

81. Cavadas PC, Landin L, Ibañez J. Bilateral hand transplantation: result at 20 months. J Hand Surg Eur Vol 2009;34:434-43.

82. Weissenbacher A, Pierer G, Gabl M, Ninkovic M, Hautz T, et al. VCA at innsbruck medical university - an update 14 years after the first hand transplantation. Transplantation 2014;98:45.

83. Francois CG, Breidenbach WC, Maldonado C, Kakoulidis TP, Hodges A, et al. Hand transplantation: comparisons and observations of the first four clinical cases. Microsurgery 2000;20:360-71.

84. Pei G, Gu L, Yu L. A preliminary report of two cases of human hand allograft. Zhonghua Yi Xue Za Zhi 2000;80:417-21. (in Chinese)

85. Jones JW, Gruber SA, Barker JH, Breidenbach WC. Successful hand transplantation: one-year follow-up. N Engl J Med 2000;343:468-73.

86. Ben-Amotz O, Kruger EA, McAndrew C, Lantieri L, Bozentka D, et al. Logistics in coordinating the first adult transatlantic bilateral hand transplant: lessons learned. Plast Reconstr Surg 2018;142:730-5.

87. Carty MJ, Zuker R, Cavadas P, Pribaz JJ, Talbot SG, et al. The case for lower extremity allotransplantation. Plast Reconstr Surg 2013;131:1272-7.

88. Mendenhall SD, Brown S, Ben-Amotz O, Neumeister MW, Levin LS. Building a hand and upper extremity transplantation program: lessons learned from the first 20 years of vascularized composite allotransplantation. Hand (N Y) 2018.

89. Elliott RM, Tintle SM, Levin LS. Upper extremity transplantation: current concepts and challenges in an emerging field. Curr Rev Musculoskelet Med 2014;7:83-8.

90. Colen DL, Carney MJ, Shubinets V, Lanni MA, Liu T, et al. Soft-tissue reconstruction of the complicated knee arthroplasty: principles and predictors of salvage. Plast Reconstr Surg 2018;141:1040-8.

91. Magill G, Benedict J, Plock JA, Krones T, Gorantla VS. Existing and evolving bioethical dilemmas, challenges and controversies in vascularized composite allotransplantation - an international perspective from the brocher bioethics working group. Transplantation 2019;103:1746-51.

92. Kubiak CA, Etra JW, Brandacher G, Kemp SWP, Kung TA, et al. Prosthetic rehabilitation and vascularized composite allotransplantation following upper limb loss. Plast Reconstr Surg 2019;143:1688-701.

93. Mathes DW, Schlenker R, Ploplys E, Vedder N. A survey of north american hand surgeons on their current attitudes toward hand transplantation. J Hand Surg Am 2009;34:808-14.

94. Lee WPA, Shores JT, Brandacher G. From auto- to allotransplantation: immunomodulatory protocol for hand and arm transplantation. J Reconstr Microsurg 2018;34:683-4.

95. Doumit G, Gharb BB, Rampazzo A, Papay F, Siemionow MZ, et al. Pediatric vascularized composite allotransplantation. Ann Plast Surg 2014;73:445-50.

96. Brandacher G, Gorantla VS, Lee WPA. Hand allotransplantation. Semin Plast Surg 2010;24:11-7.

97. Grahammer J, Weissenbacher A, Zelger BG, Zelger B, Boesmueller M, et al. Benefits and limitations of belatacept in 4 hand-transplanted patients. Am J Transplant 2017;17:3228-35.

98. Diaz-Siso JR, Fischer S, Sisk GC, Bueno E, Kueckelhaus M, et al. Initial experience of dual maintenance immunosuppression with steroid withdrawal in vascular composite tissue allotransplantation. Am J Transplant 2015;15:1421-31.

99. Petruzzo P, Gazarian A, Kanitakis J, Parmentier H, Guigal V, et al. Outcomes after bilateral hand allotransplantation. Ann Surg 2015;261:213-20.

100. Messner F, Hautz T. The innsbruck handtransplant program: eighteen years of experience. Am J Transplant 2019;19:615.

101. Schneeberger S, Gorantla VS, Brandacher G, Zeevi A, Demetris AJ, et al. Upper-extremity transplantation using a cell-based protocol to minimize immunosuppression. Ann Surg 2013;257:345-51.

102. Sutter D, Dzhonova DV, Prost JC, Bovet C, Banz Y, et al. Delivery of rapamycin using in situ forming implants promotes immunoregulation and vascularized composite allograft survival. Sci Rep 2019;9:9269.

103. Sarhane KA, Tuffaha SH, Broyles JM, Ibrahim AE, Khalifian S, et al. A critical analysis of rejection in vascularized composite allotransplantation: clinical, cellular and molecular aspects, current challenges, and novel concepts. Front Immunol 2013;4:406.

104. Petruzzo P, Lanzetta M, Dubernard JM, et al. The international registry on hand and composite tissue transplantation. Transplantation 2010;90:1590-4.

105. Kaufman CL, Ouseph R, Blair B, Kutz JE, Tsai TM, et al. Graft vasculopathy in clinical hand transplantation. Am J Transplant 2012;12:1004-16

106. Schneeberger S, Gorantla VS, Hautz T, Pulikkottil B, Margreiter R, et al. Immunosuppression and rejection in human hand transplantation. Transplant Proc 2009;41:472-5.

107. Ninkovic M, Weissenbacher A, Gabl M, Pierer G, Pratschke J, et al. Functional outcome after hand and forearm transplantation: what can be achieved? Hand Clin 2011;27:455-65. 
108. Severance G, Walsh L. Rehabilitation after bilateral hand transplantation in the quadrimembral patient: review and recommendations. Tech Hand Up Extrem Surg 2013;17:215-20.

109. Datta D, Selvarajah K, Davey N. Functional outcome of patients with proximal upper limb deficiency - acquired and congenital. Clin Rehabil 2004;18:172-7.

110. Kaufman CL, Breidenbach W. World experience after more than a decade of clinical hand transplantation: update from the Louisville hand transplant program. Hand Clin 2011;27:417-21.

111. Salminger S, Sturma A, Roche AD, Hruby LA, Paternostro-Sluga T, et al. Functional and psychosocial outcomes of hand transplantation compared with prosthetic fitting in below-elbow amputees: a multicenter cohort study. PLoS One 2016;11:e162507.

112. Shores JT, Brandacher G, Lee WPA. Hand and upper extremity transplantation. Plast Reconstr Surg 2015;135:351-60e

113. Schneeberger S, Zelger B, Ninkovic M, Margreiter R. Transplantation of the hand. Transplant Rev 2005;19:100-7. 